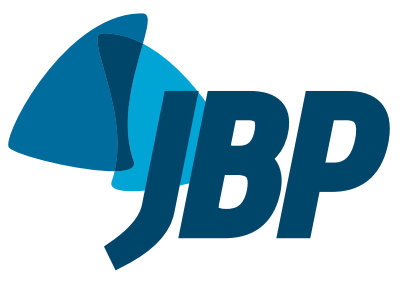

\title{
Clinical and functional correlations of the difference between slow vital capacity and FVC
}

\author{
Jonathan Jerias Fernandez ${ }^{1,2}(\mathbb{D})$, Maria Vera Cruz de Oliveira Castellano ${ }^{3}(\mathbb{D})$, \\ Flavia de Almeida Filardo Vianna ${ }^{3}$ (D) , Sérgio Roberto Nacif ${ }^{1}(\mathbb{D})$, \\ Roberto Rodrigues Junior ${ }^{4}$, Sílvia Carla Sousa Rodrigues ${ }^{1,5}$ (D)
}

1. Laboratório de Função Pulmonar, Instituto de Assistência ao Servidor Público Estadual de São Paulo IAMSPE - São Paulo (SP), Brasil.

2. Universidade Federal do $A B C$, Santo André (SP) Brasil.

3. Serviço de Doenças do Aparelho Respiratório, Hospital do Servidor Público Estadual de São Paulo, São Paulo (SP) Brasil.

4. Disciplina de Pneumologia, Faculdade de Medicina do ABC, Santo André (SP) Brasil.

5. Laboratório de Função Pulmonar, Alta Excelência Diagnóstica, São Paulo (SP) Brasil.

Submitted: 17 October 2018

Accepted: 6 May 2019

Study carried out at the Instituto de Assistência ao Servidor Público Estadual de São Paulo - IAMSPE - São Paulo (SP) Brasil.

\begin{abstract}
Objective: To evaluate the relationship that the difference between slow vital capacity (SVC) and FVC ( $\triangle S V C-F V C)$ has with demographic, clinical, and pulmonary function data. Methods: This was an analytical cross-sectional study in which participants completed a respiratory health questionnaire, as well as undergoing spirometry and plethysmography. The sample was divided into two groups: $\triangle$ SVC-FVC $\geq 200 \mathrm{~mL}$ and $\Delta$ SVC-FVC $<200$ $\mathrm{mL}$. The intergroup correlations were analyzed, and binomial logistic regression analysis was performed. Results: The sample comprised 187 individuals. In the sample as a whole, the mean $\triangle S V C-F V C$ was $0.17 \pm 0.14 \mathrm{~L}$, and 61 individuals $(32.62 \%$ ) had a $\triangle S V C$ FVC $\geq 200 \mathrm{~mL}$. The use of an SVC maneuver reduced the prevalence of nonspecific lung disease and of normal spirometry results by revealing obstructive lung disease (OLD). In the final logistic regression model (adjusted for weight and body mass index > $30 \mathrm{~kg} / \mathrm{m}^{2}$ ), OLD and findings of air trapping (high functional residual capacity and a low inspiratory capacity/TLC ratio) were predictors of a $\triangle S V C-F V C \geq 200 \mathrm{~mL}$. The chance of a bronchodilator response was found to be greater in the $\triangle$ SVC-FVC $\geq 200 \mathrm{~mL}$ group: for FEV1 (OR = 4.38; 95\% Cl: 1.45-13.26); and for FVC (OR = 3.83; 95\% Cl: 1.26 11.71). Conclusions: The use of an SVC maneuver appears to decrease the prevalence of nonspecific lung disease and of normal spirometry results. Individuals with a $\triangle$ SVC-FVC $\geq 200 \mathrm{~mL}$, which is probably the result of OLD and air trapping, are apparently more likely to respond to bronchodilator administration.
\end{abstract}

Keywords: Vital capacity; Plethysmography; Airway obstruction.

\section{INTRODUCTION}

American Thoracic Society/European Respiratory Society (ATS/ERS) guidelines recommend the use of slow VC (SVC) as the denominator to calculate the Tiffeneau index. ${ }^{(1)}$ Despite this recommendation, SVC maneuvers are not routinely used in most pulmonary function laboratories in Brazil.

VC is determined by measuring the volume of air in the lungs after a maximal inhalation and after a maximal exhalation, i.e., TLC and RV, respectively, which include lung/chest wall compliance and elastic recoil, respiratory muscle strength, alveolar collapse, and airway closure.(2-4) In individuals with no chest wall or respiratory muscle abnormalities, TLC is determined by lung elastic recoil. ${ }^{(5)}$ In young individuals, RV is primarily determined by static factors (chest wall elastic recoil and respiratory muscle pressure), whereas, in elderly individuals and in those presenting with airflow limitation, RV is determined by dynamic factors (expiratory flow limitation and airway closure). ${ }^{(3,6)}$

In normal individuals, VC reflects the properties of the lung parenchyma, whereas, in those with chronic obstructive lung disease, it reflects the properties of the airways. ${ }^{(5)}$ In patients with airflow limitation, airway closure occurs at high lung volumes. (7) During an FVC maneuver, dynamic compression and airway collapse can lead to premature airway closure, thus reducing FVC. Reduced thoracic gas compression during an SVC maneuver explains the fact that, even in healthy individuals, there is a difference between SVC and FVC ( $\triangle$ SVC-FVC), which is more pronounced in patients with obstructive lung disease (OLD). ${ }^{(5)}$

Few studies have examined the association of $\triangle$ SVC-FVC with demographic characteristics, lung function, respiratory

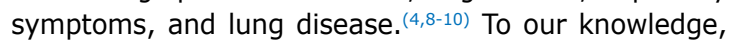
there have been no studies evaluating bronchodilator response in relation to $\triangle$ SVC-FVC.

The primary objective of the present study was to examine the association of $\triangle$ SVC-FVC with demographic variables, spirometric parameters, plethysmographic parameters, bronchodilator response, and lung function, as well as to identify factors independently associated with a $\triangle S V C-F V C \geq 200 \mathrm{~mL}$. A secondary objective was to examine the association of $\triangle$ SVC-FVC with the severity of OLD, respiratory symptoms, and clinical diagnosis, as well as to compare the spirometry results obtained with the use of FVC maneuvers alone and those obtained with the combined use of FVC and SVC maneuvers. 


\section{METHODS}

This was an analytical cross-sectional study. The study sample consisted of patients referred for pulmonary function testing between October 21, 2013 and July 28, 2015 at the Instituto de Assistência Médica ao Servidor Público Estadual (IAMSPE, Institute for the Medical Care of State Civil Servants), located in the city of São Paulo, Brazil. The study was approved by the Research Ethics Committee of the IAMSPE (Ruling no. 373,763, August 5, 2013).

Patients were randomly invited to participate in the study, and those who agreed gave written informed consent and completed a respiratory questionnaire, ${ }^{(11)}$ which was administered by a nurse who is also a pulmonary function technician certified by the Brazilian Thoracic Association.

The inclusion criteria were being an outpatient and meeting the criteria established in studies reporting reference values for spirometry and plethysmography in Brazil. ${ }^{(12,13)}$ The exclusion criteria were having performed spirometric or plethysmographic maneuvers that failed to meet the ATS/ERS acceptability and reproducibility criteria $^{(14,15)}$ and presenting with SVC < FVC.

Figure 1 shows a flow chart of the sample selection process. All participants performed SVC, FVC, and plethysmographic maneuvers (in this order) using a Collins system (Ferraris Respiratory, Louisville, CO, USA). All tests were performed by the aforementioned nurse, with participants in a sitting position and wearing a nose clip.

All tests were reviewed by the principal investigator and the coordinator of the pulmonary function laboratory. Emphasis was placed on the quality of inspiratory capacity (IC) maneuvers, which were performed in a relaxed manner after at least three stable breaths. IC was defined as the average of three reproducible measurements (a variability of $\leq 100 \mathrm{~mL}$ ). The highest SVC value was selected from three measurements with a reproducibility of $\leq 100 \mathrm{~mL}$. During FVC maneuvers, the difference between the two highest FVC and FEV values was $\leq 150 \mathrm{~mL}$ and that between the two highest PEF values was $\leq 10 \%$. The highest FVC and $\mathrm{FEV}_{1}$ values were selected from those obtained during acceptable maneuvers, in accordance with the criterion of PEF reproducibility. ${ }^{(14,16)}$

With regard to plethysmography, functional residual capacity (FRC) was calculated from thoracic gas volume, at the end of tidal volume exhalation. TLC and RV were calculated by the following formulas: TLC = IC + FRC and RV $=$ TLC - SVC. ${ }^{(15)}$

The results were interpreted in accordance with the ATS/ERS criteria. (1) Spirometry results were considered normal when values were above the lower limit of normal; OLD was defined as an $\mathrm{FEV}_{1} /(\mathrm{F}) \mathrm{VC}$ ratio below the lower limit of normal; nonspecific lung disease (NLD) was defined as a proportional reduction in (F) VC and $\mathrm{FEV}_{1}$; and OLD with reduced (F)VC was defined as the presence of OLD associated with a reduction in (F)VC. First, we analyzed the spirometry results obtained with the use of FVC maneuvers alone; then, we analyzed those obtained with the combined use of FVC and SVC maneuvers.

Plethysmographic variables were then analyzed. Given that specific airway conductance (sGaw) is also a parameter of airflow limitation, sGaw values of < 0.12 [with or without reduced $\mathrm{FEV}_{1} /(\mathrm{F}) \mathrm{VC}$ ratio] were interpreted as indicative of OLD. ${ }^{(17,18)}$ Air trapping was defined as an RV $>130 \%$, and lung hyperinflation was defined as a TLC $>120 \%$. All patients with reduced TLC were diagnosed with restrictive lung disease. ${ }^{(19)}$ In such cases, the use of a fixed threshold is acceptable because of decreasing dispersion of the data around the predicted equation line. ${ }^{(20)}$ The difference between TLC and FVC, a theoretical measure designated forced RV (FRV), was calculated and expressed as absolute values and as a percentage of the predicted values.

OLD was classified as mild ( $\mathrm{FEV}_{1} \geq 60 \%$ ), moderate $\left(\mathrm{FEV}_{1}=41-59 \%\right)$, or severe $\left(\mathrm{FEV}_{1} \leq 40 \%\right)$, in accordance with British Thoracic Society criteria. ${ }^{(21)}$

A subgroup of patients with OLD underwent spirometry 20 min after administration of a bronchodilator (400 $\mu \mathrm{g}$ of albuterol aerosol). A significant bronchodilator response was characterized by FVC and $\mathrm{FEV}_{1} \geq 200$ $\mathrm{mL}$ and $\geq 7 \%$ of predicted; SVC $\geq 250 \mathrm{~mL}$ and $\geq 8 \%$ of predicted; and IC $\geq 300 \mathrm{~mL}$. ${ }^{\text {(22) }}$

The study sample was divided into two groups: $\triangle$ SVC-FVC $<200$, comprising patients in whom $\Delta$ SVCFVC was $<200 \mathrm{~mL}$ (as assessed before bronchodilator administration); and $\triangle$ SVC-FVC $\geq 200$, comprising patients in whom $\triangle$ SVC-FVC was $\geq 200 \mathrm{~mL}$ (as assessed before bronchodilator administration). The 200-mL threshold was used because it is higher than that used in order to assess reproducibility, as well as being higher than the mean $\triangle$ SVC-FVC values observed in healthy individuals. ${ }^{(8,9,23)}$

\section{Statistical analysis}

All statistical analyses were performed with the IBM SPSS Statistics software package, version 21.0 (IBM Corporation, Armonk, NY, USA). Data were expressed as means and standard deviations for quantitative variables and as absolute numbers and proportions for categorical variables. Normality of data distribution was assessed with the Kolmogorov-Smirnov test with Lilliefors correction.

Functional, demographic, and clinical parameters were compared between the groups with the use of the Student's t-test (for data with normal distribution) or the Mann-Whitney $U$ test (for data with non-normal distribution). The kappa statistic was used in order to assess the agreement between the spirometry results obtained with FVC maneuvers alone and those obtained with FVC and SVC maneuvers in combination. Categorical variables were compared by the chi-square test or Fisher's exact test.

Correlations of $\triangle$ SVC-FVC with demographic, clinical, and functional variables were analyzed with Pearson's or Spearman's correlation coefficient, the former being 


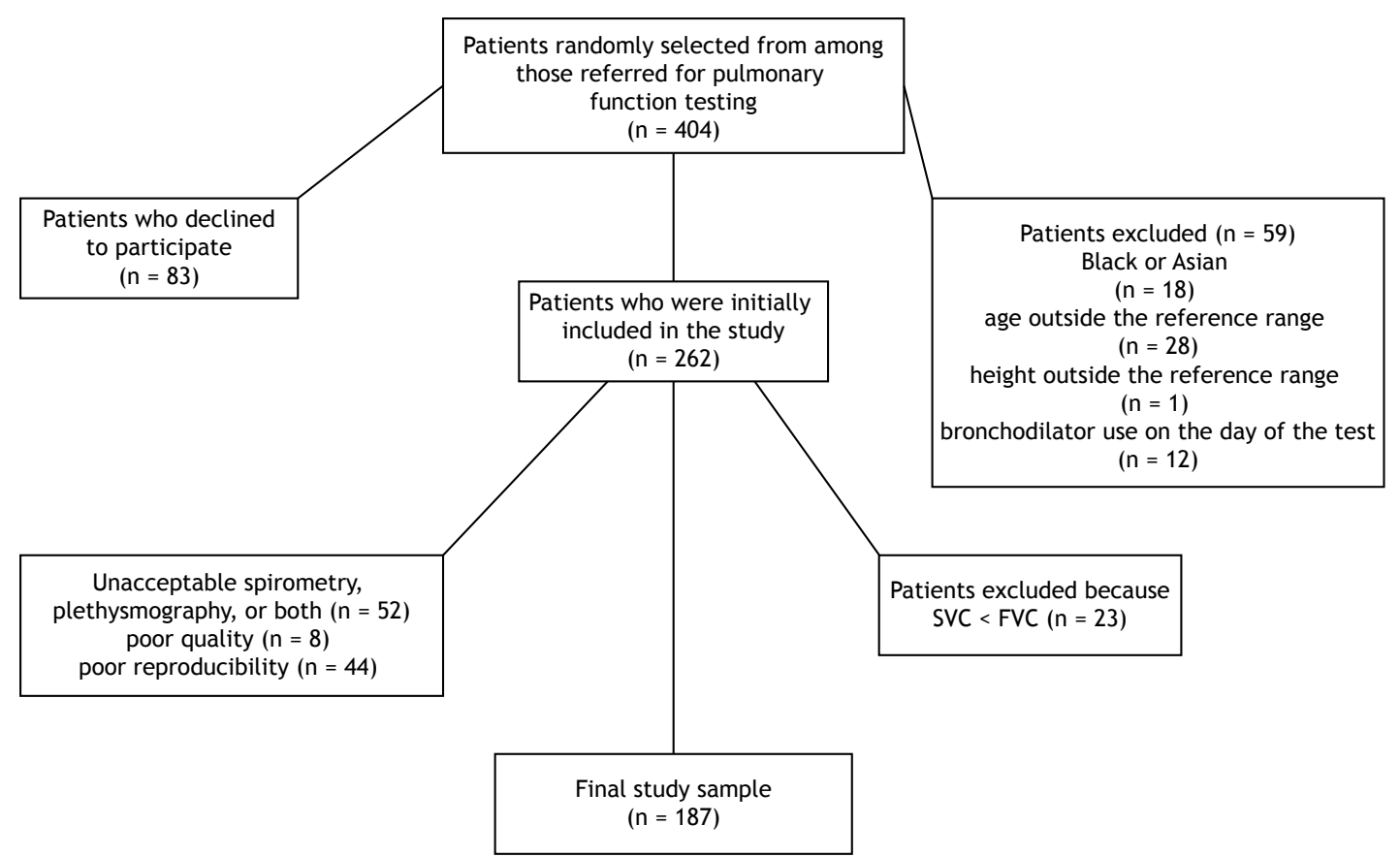

Figure 1. Flow chart of the sample selection process. SVC: slow vital capacity.

used for data with normal distribution and the latter being used for data with non-normal distribution.

Logistic regression analysis was performed to identify independent predictors of a $\triangle$ SVC-FVC $\geq 200 \mathrm{~mL}$. First, a single logistic regression analysis was performed to determine the OR for each demographic variable. Then, a binomial logistic regression analysis was performed to evaluate spirometric and plethysmographic parameters, crude and adjusted ORs being calculated (for the variables that were significant in the single logistic regression model) to predict a $\triangle S V C-F V C \geq 200 \mathrm{~mL}$.

A multiple logistic regression analysis was performed to determine whether a $\triangle$ SVC-FVC $\geq 200 \mathrm{~mL}$ was a predictor of significant changes in spirometric

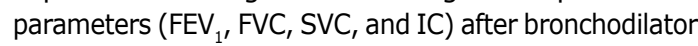
administration. It was also used in order to determine whether a $\triangle$ SVC-FVC $\geq 200 \mathrm{~mL}$ was predictive of normal TLC in cases in which spirometry results were indicative of NLD or of OLD with reduced FVC and a significant bronchodilator response. The level of significance was set at $5 \%$ for all analyses except the single logistic regression model, in which the level of significance was set at $p<0.20$.

\section{RESULTS}

A total of 187 patients were selected (Figure 1). The general characteristics of the recruited population and a comparison between the two study groups are shown in Table 1. The mean age was $59.01 \pm 12.80$ years, and 126 patients $(67.40 \%)$ were female. Mean height and weight were $159.90 \pm 9.60 \mathrm{~cm}$ and $78.46 \pm 18.48 \mathrm{~kg}$, respectively. Mean $\triangle$ SVC-FVC was $0.17 \mathrm{~L}$, a $\triangle$ SVC-FVC $\geq 200 \mathrm{~mL}$ being observed in 61 participants $(32.62 \%)$. A $\triangle$ SVC-FVC $\geq 200 \mathrm{~mL}$ was observed in 28 (45.90\%) of the 61 male participants and in $33(26.20 \%)$ of the 126 female participants $(p=0.007)$. Height and weight were higher in the $\triangle S V C$-FVC $\geq 200$ group than in the $\triangle$ SVC-FVC group $<200$ ( $p=0.002$ and $p=0.017$, respectively). There were no significant differences between the two groups regarding body mass index (BMI) or clinical parameters (smoking and dyspnea). The Tiffeneau index was lower in the $\triangle$ SVC-FVC $\geq 200$ group than in the $\triangle$ SVC-FVC $<200$ group, whereas lung volumes were higher in the former than in the latter. A $\triangle$ SVC-FVC was significantly more common in patients with OLD, regardless of the severity of airflow obstruction.

Table 2 shows the agreement between the spirometry results obtained with FVC maneuvers alone and those obtained with FVC and SVC maneuvers in combination (kappa $=0.653)$. Of the 73 normal spirometry results obtained when FVC maneuvers were used in isolation, 21 were reclassified as OLD when FVC and SVC maneuvers were used in combination. Of the 32 cases that were diagnosed as NLD when FVC maneuvers were used in isolation, 17 were reclassified when FVC and SVC maneuvers were used in combination. Of the 28 spirometry results interpreted as OLD with reduced FVC when FVC maneuvers were used in isolation, 8 were reclassified as OLD when FVC and SVC maneuvers were used in combination. Of the 91 cases that were diagnosed as OLD when FVC and SVC maneuvers were used in combination, only 54 had been diagnosed as OLD when FVC maneuvers were used in isolation. When normal spirometry results were excluded from the analysis, the kappa statistic was lower (0.506).

Reports of improvement in wheezing after bronchodilator administration were more common in the $\triangle$ SVC-FVC 
Table 1. General and functional characteristics of the sample as a whole and of the two study groups.

\begin{tabular}{|c|c|c|c|c|}
\hline \multirow[t]{2}{*}{ Parameter } & \multirow{2}{*}{$\begin{array}{l}\text { Total sample } \\
\text { (n = 187) }\end{array}$} & \multicolumn{2}{|c|}{ Group } & \multirow[t]{2}{*}{$\mathbf{p}$} \\
\hline & & $\begin{array}{c}\Delta S V C-F V C<200 \mathrm{~mL} \\
(\mathrm{n}=126)\end{array}$ & $\begin{array}{c}\Delta S V C-F V C \geq 200 \mathrm{~mL} \\
(\mathrm{n}=61)\end{array}$ & \\
\hline Male sex & $61(32.62)$ & $33(26.20)$ & $28(45.90)$ & $0.007^{*}$ \\
\hline Female sex & $126(67.40)$ & $93(73.81)$ & $33(54.10)$ & \\
\hline Age, years & $59.01 \pm 12.80$ & $59.70 \pm 13.11$ & $57.61 \pm 12.11$ & $0.300^{*}$ \\
\hline Height, cm & $159.90 \pm 9.60$ & $158.37 \pm 9.23$ & $163.00 \pm 9.70$ & $0.002^{*}$ \\
\hline Weight, kg & $78.46 \pm 18.48$ & $76.25 \pm 16.86$ & $83.12 \pm 20.90$ & $0.017^{*}$ \\
\hline $\mathrm{BMI}, \mathrm{kg} / \mathrm{m}^{2}$ & $30.45 \pm 6.40$ & $30.26 \pm 6.20$ & $30.85 \pm 6.84$ & $0.553^{*}$ \\
\hline Smoking history, pack-years & $18.30 \pm 27.20$ & $16.17 \pm 25.82$ & $22.70 \pm 29.60$ & $0.110^{* *}$ \\
\hline Dyspnea, mMRC scale score & $1.0[0.0-4.0]$ & $1.0[0.0-4.0]$ & $1.0[0.0-4.0]$ & $0.570^{* *}$ \\
\hline FVC, L & $2.83 \pm 0.91$ & $2.73 \pm 0.90$ & $3.03 \pm 0.90$ & $0.035^{* *}$ \\
\hline FVC, \% predicted & $84.72 \pm 17.35$ & $85.11 \pm 17.67$ & $83.90 \pm 16.79$ & $0.666^{*}$ \\
\hline $\mathrm{FEV}_{1}, \mathrm{~L}$ & $2.02 \pm 0.73$ & $1.99 \pm 0.71$ & $2.08 \pm 0.76$ & $0.418^{*}$ \\
\hline $\mathrm{FEV}_{1}, \%$ predicted & $75.00 \pm 18.94$ & $76.56 \pm 18.44$ & $71.87 \pm 19.58$ & $0.116^{*}$ \\
\hline $\mathrm{FEV}_{1} / \mathrm{FVC}$ & $0.71 \pm 0.12$ & $0.73 \pm 0.10$ & $0.68 \pm 0.12$ & $0.017^{* *}$ \\
\hline PEF, L/s & $6.92 \pm 5.00$ & $6.97 \pm 5.87$ & $6.82 \pm 2.33$ & $0.587^{* *}$ \\
\hline SVC, L & $3.00 \pm 0.94$ & $2.83 \pm 0.91$ & $3.35 \pm 0.92$ & $<0.001^{*}$ \\
\hline SVC, \% predicted & $89.20 \pm 17.00$ & $87.50 \pm 17.06$ & $92.70 \pm 16.50$ & $0.049^{*}$ \\
\hline IC, L & $2.12 \pm 0.63$ & $2.05 \pm 0.62$ & $2.26 \pm 0.63$ & $0.034^{*}$ \\
\hline $\mathrm{FEV}_{1} / \mathrm{SVC}$ & $0.67 \pm 0.11$ & $0.70 \pm 0.10$ & $0.61 \pm 0.11$ & $<0.001^{* *}$ \\
\hline FRC, L & $2.93 \pm 0.94$ & $2.79 \pm 0.90$ & $3.21 \pm 0.97$ & $0.002^{* *}$ \\
\hline TLC, L & $5.05 \pm 1.27$ & $4.84 \pm 1.22$ & $5.47 \pm 1.27$ & $0.001^{* *}$ \\
\hline TLC, \% predicted & $94.44 \pm 16.70$ & $93.73 \pm 16.86$ & $95.92 \pm 16.34$ & $0.402^{*}$ \\
\hline $\mathrm{RV}, \mathrm{L}$ & $2.05 \pm 0.79$ & $2.01 \pm 0.76$ & $2.12 \pm 0.86$ & $0.185^{* *}$ \\
\hline RV, \% predicted & $127.34 \pm 45.00$ & $129.17 \pm 43.61$ & $123.54 \pm 47.90$ & $0.424^{*}$ \\
\hline $\mathrm{RV} / \mathrm{TLC}$ & $0.41 \pm 0.12$ & $0.42 \pm 0.11$ & $0.39 \pm 0.12$ & $0.086^{*}$ \\
\hline IC/TLC & $0.42 \pm 0.10$ & $0.43 \pm 0.09$ & $0.42 \pm 0.09$ & $0.495^{*}$ \\
\hline sGaw, L/s/cmH ${ }_{2} \mathrm{O}$ & $0.12 \pm 0.08$ & $0.12 \pm 0.08$ & $0.11 \pm 0.07$ & $0.380^{* *}$ \\
\hline FRV, L & $2.22 \pm 0.81$ & $2.11 \pm 0.76$ & $2.44 \pm 0.85$ & $0.02^{* *}$ \\
\hline FRV, \% predicted & $155.71 \pm 41.00$ & $152.00 \pm 36.51$ & $163.84 \pm 48.26$ & $0.059^{*}$ \\
\hline$\triangle S V C-F V C, L$ & $0.17 \pm 0.14$ & $0.095 \pm 0.052$ & $0.321 \pm 0.132$ & $<0.001^{*}$ \\
\hline
\end{tabular}

$\triangle$ SVC-FVC: difference between slow VC and FVC; BMI: body mass index; mMRC: modified Medical Research Council; SVC: slow vital capacity; FRC: functional residual capacity; IC: inspiratory capacity; sGaw: specific airway conductance; and FRV: forced residual volume. aValues expressed as $\mathrm{n}(\%)$, mean \pm SD, or median [minimummaximum]. *Student's t-test. **Mann-Whitney $U$ test.

Table 2. Agreement between the spirometry results obtained with FVC maneuvers alone and those obtained with FVC and slow vital capacity maneuvers in combination. ${ }^{\mathrm{a}, \mathrm{b}}$

\begin{tabular}{|c|c|c|c|c|c|c|c|c|}
\hline \multicolumn{2}{|c|}{ Functional diagnosis } & \multicolumn{4}{|c|}{ FVC + SVC maneuvers } & \multirow[t]{2}{*}{ Total } & \multirow[t]{2}{*}{ kappa } & \multirow[t]{2}{*}{$\mathbf{p}$} \\
\hline & & Normal & OLD & $\begin{array}{l}\text { OLD with } \\
\text { reduced VC }\end{array}$ & NLD & & & \\
\hline \multirow{5}{*}{ FVC maneuvers } & Normal & 52 & 21 & 0 & 0 & 73 & \multirow{5}{*}{0.653} & \multirow{5}{*}{$<0.001$} \\
\hline & OLD & 0 & 54 & 0 & 0 & 54 & & \\
\hline & OLD with reduced FVC & 0 & 8 & 20 & 0 & 28 & & \\
\hline & NLD & 4 & 8 & 5 & 15 & 32 & & \\
\hline & Total & 56 & 91 & 25 & 15 & 187 & & \\
\hline
\end{tabular}

SVC: slow vital capacity; OLD: obstructive lung disease; and NLD: nonspecific lung disease. ${ }^{\text {Values expressed as }}$

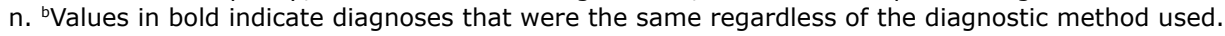

$\geq 200$ group than in the $\triangle$ SVC-FVC $<200$ group ( $p=$ 0.04 ), as assessed by the aforementioned respiratory questionnaire. $^{(11)}$ Of the 17 participants with a history of tuberculosis, only 1 was in the $\triangle$ SVC-FVC $\geq 200$ group ( $p$ $=0.011$ ). There were no significant differences between the two groups regarding clinical diagnosis (Table 3 ).
The use of Pearson's or Spearman's correlation coefficient (data not shown) showed that $\triangle$ SVC-FVC correlated positively with height, FVC (L), SVC (L), SVC (\% predicted), IC (L), TLC (L), and FRV (\% predicted), as well as correlating negatively with $\mathrm{FEV}_{1} /(\mathrm{F}) \mathrm{VC}, \mathrm{RV}$ (\% predicted), and RV/TLC. 
Table 3. Clinical diagnoses based on a $<200 \mathrm{~mL}$ difference between slow VC and FVC in comparison with those based on $a \geq 200 \mathrm{~mL}$ difference between slow VC and FVC.

\begin{tabular}{|c|c|c|c|c|c|}
\hline \multirow[t]{2}{*}{ Diagnosis } & \multicolumn{2}{|c|}{$\begin{array}{c}\Delta S V C-F V C<200 \mathrm{~mL} \\
(\mathrm{n}=126)\end{array}$} & \multicolumn{2}{|c|}{$\begin{array}{c}\Delta S V C-F V C \geq 200 \mathrm{~mL} \\
(\mathrm{n}=61)\end{array}$} & \multirow[t]{2}{*}{$p^{*}$} \\
\hline & $\mathbf{n}$ & $\%$ & $n$ & $\%$ & \\
\hline Unknown & 33 & 26.20 & 16 & 26.23 & 0.566 \\
\hline Asthma & 31 & 24.40 & 14 & 23.00 & \\
\hline COPD & 15 & 11.80 & 10 & 16.40 & \\
\hline ILD & 17 & 13.40 & 7 & 11.50 & \\
\hline Rhinitis & 6 & 4.70 & 1 & 1.60 & \\
\hline Bronchiolitis & 7 & 5.50 & 3 & 4.90 & \\
\hline Asthma + other & 5 & 3.90 & 1 & 1.60 & \\
\hline COPD + other & 0 & 0.00 & 2 & 3.30 & \\
\hline Other & 12 & 9.40 & 7 & 11.50 & \\
\hline
\end{tabular}

$\triangle$ SVC-FVC: difference between slow VC and FVC; and ILD: interstitial lung disease. *Fisher's exact test.

Table 4. Evaluation of demographic parameters (initial model) and functional parameters (final model) predicting a $\geq$ $200 \mathrm{~mL}$ difference between slow VC and FVC by logistic regression.

\begin{tabular}{|c|c|c|}
\hline Demographic parameter & $\begin{array}{l}\text { Initial mod } \\
\text { OR }(95 \% \mathrm{CI})\end{array}$ & p \\
\hline Age, years & $1.348(0.501-3.629)$ & 0.554 \\
\hline Female sex & $0.774(0.318-1.883)$ & 0.572 \\
\hline Height, cm & $1.016(0.947-1.090)$ & 0.655 \\
\hline Weight, kg & $1.036(0.983-1.091)$ & 0.183 \\
\hline $\mathrm{BMI}, \mathrm{kg} / \mathrm{m}^{2}$ & $1.038(0.887-1.215)$ & 0.644 \\
\hline $\mathrm{BMI}>30 \mathrm{~kg} / \mathrm{m}^{2}$ & $5.075(1.583-16.270)$ & 0.006 \\
\hline \multicolumn{3}{|c|}{ Final model } \\
\hline Functional parameter & Crude OR (95\% CI) & Adjusted OR (95\% CI) \\
\hline FVC, L & $1.425(1.015-2.002)$ & $1.020(0.687-1.513)$ \\
\hline FVC, \% predicted & $0.996(0.979-1.014)$ & $0.992(0.974-1.011)$ \\
\hline $\mathrm{FEV}_{1}, \mathrm{~L}$ & $1.190(0.782-1.812)$ & $0.711(0.426-1.188)$ \\
\hline $\mathrm{FEV}_{1}, \%$ predicted & $0.987(0.971-1.003)$ & $0.980(0.962-0.998)$ \\
\hline $\mathrm{FEV}_{1} / \mathrm{FVC}$ & $0.967(0.940-0.994)$ & $0.952(0.922-0.983)$ \\
\hline SVC, L & $1.831(1.296-2.586)$ & $1.399(0.951-2.058)$ \\
\hline SVC, \% predicted & $1.019(1.000-1.038)$ & $1.018(0.997-1.038)$ \\
\hline IC, L & $1.695(1.035-2.776)$ & $1.014(0.557-1.845)$ \\
\hline $\mathrm{FEV}_{1} / \mathrm{SVC}$ & $0.931(0.902-0.960)$ & $0.908(0.875-0.943)$ \\
\hline TLC, L & $1.492(1.156-1.924)$ & $1.282(0.895-1.685)$ \\
\hline TLC, \% predicted & $1.008(0.989-1.027)$ & $1.016(0.995-1.037)$ \\
\hline $\mathrm{RV}, \mathrm{L}$ & $1.188(0.811-1.742)$ & $1.201(0.806-1.790)$ \\
\hline $\mathrm{RV}$, \% predicted & $0.997(0.990-1.004)$ & $1.002(0.994-1.009)$ \\
\hline $\mathrm{RV} / \mathrm{TLC}$ & $0.099(0.007-1.400)$ & $0.561(0.030-10.561)$ \\
\hline FRC, L & $1.614(1.155-2.255)$ & $1.532(1.063-2.808)$ \\
\hline sGaw, $\mathrm{cmH}_{2} \mathrm{O} / \mathrm{L} / \mathrm{s}$ & $0.143(0.003-8.005)$ & $0.032(0.000-3.000)$ \\
\hline IC/TLC & $0.988(0.955-1.022)$ & $0.956(0.917-0.998)$ \\
\hline FRV, L & $1.692(1.142-2.505)$ & $1.697(1.119-2.572)$ \\
\hline FRV, \% predicted & $1.007(1.000-1.015)$ & $1.000(0.992-1.009)$ \\
\hline $\mathrm{OLD}_{\mathrm{FVC}}$ & $1.677(0.906-3.107)$ & $1.879(0.948-3.723)$ \\
\hline $\mathrm{OLD}_{\text {sVc }}$ & $5.597(2.543-12.322)$ & $9.444(3.708-24.049)$ \\
\hline $\mathrm{OLD}_{\text {PLET }}$ & $2.250(1.151-4.397)$ & $3.225(1.497-6.948)$ \\
\hline
\end{tabular}

BMI: body mass index; SVC: slow vital capacity; IC: inspiratory capacity; FRC: functional residual capacity; sGaw: specific airway conductance; FRV: forced residual volume; OLD: obstructive lung disease; PLET: plethysmography.

As can be seen in Table 4, binomial logistic regression showed that weight and BMI $>30 \mathrm{~kg} / \mathrm{m}^{2}$ were predictors of a $\triangle$ SVC-FVC $\geq 200 \mathrm{~mL}(\mathrm{p}<0.20)$. Crude and adjusted ORs were calculated for weight and BMI >
$30 \mathrm{~kg} / \mathrm{m}^{2}$ by means of a logistic regression analysis to evaluate spirometric and plethysmographic parameters. Reduced $\mathrm{FEV}_{1}$ ( $\%$ predicted), $\mathrm{FEV}_{1} / \mathrm{FVC}, \mathrm{FEV}_{1} / \mathrm{SVC}$, and IC/TLC, as well as increased FRC (L) and FRV (L), 
Table 5. Multiple logistic regression analysis of bronchodilator response for a $\geq 200 \mathrm{~mL}$ difference between slow VC and FVC. ${ }^{\text {a }}$

\begin{tabular}{lcccc}
\multicolumn{1}{c}{ Parameter } & OR & $95 \%$ Cl & ${\text { Pseudo } \mathbf{r}^{2}}$ & p \\
$\mathrm{FEV}_{1}$ & 4.38 & $1.45-13.26$ & 0.112 & 0.009 \\
$\mathrm{FVC}$ & 3.83 & $1.26-11.71$ & 0.090 & 0.018 \\
$\mathrm{SVC}$ & 0.63 & $0.38-4.91$ & 0.040 & 0.630 \\
$\mathrm{IC}$ & 2.14 & $0.53-8.64$ & 0.018 & 0.284 \\
Any parameter responding positively & 4.74 & $1.65-13.56$ & 0.136 & 0.040 \\
\hline
\end{tabular}

SVC: slow vital capacity; and IC: inspiratory capacity. ${ }^{\text {In }}$ comparison with a $<200 \mathrm{~mL}$ difference.

were independent predictors of a $\triangle S V C-F V C \geq 200 \mathrm{~mL}$. Increased SVC, IC, and TLC were associated with a $\triangle$ SVC-FVC $\geq 200 \mathrm{~mL}$, albeit only in the crude model. OLD (characterized by reduced $\mathrm{FEV}_{1} / \mathrm{SVC}$, reduced sGaw, or a combination of the two) was independently associated with a $\triangle$ SVC-FVC $\geq 200 \mathrm{~mL}$.

As can be seen in Table 5, our multiple logistic regression model showed that individuals with a $\triangle$ SVCFVC $\geq 200 \mathrm{~mL}$ were more likely to show a significant change in $\mathrm{FEV}_{1}(\mathrm{OR}=4.38 ; 95 \% \mathrm{CI}: 1.45-13.26)$ and FVC (OR $=3.83 ; 95 \% \mathrm{CI}: 1.26-11.71)$ than were those with a $\triangle$ SVC-FVC $<200 \mathrm{~mL}$. However, in cases in which spirometry results were indicative of NLD or of OLD with reduced FVC and a significant bronchodilator response, a $\triangle S V C-F V C \geq 200 \mathrm{~mL}$ failed to predict normal TLC $(\mathrm{OR}=1.705 ; 95 \% \mathrm{CI}: 0.333-8.721)$.

\section{DISCUSSION}

The use of SVC and $\mathrm{FEV}_{1}$ /SVC in the present study reduced the prevalence of NLD and of normal spirometry results by revealing airflow obstruction that can go unnoticed when only FVC and $\mathrm{FEV}_{1} / \mathrm{FVC}$ are analyzed. Reductions in percent predicted $\mathrm{FEV}_{1}$ and in $\mathrm{FEV}_{1} /(\mathrm{F})$ VC, as well as the presence of OLD, together with findings suggestive of air trapping (increased FRC and reduced IC/TLC), ${ }^{(24)}$ were factors independently associated with a $\triangle$ SVC-FVC $\geq 200 \mathrm{~mL}$. A significant bronchodilator response was more likely to occur in cases in which the $\triangle$ SVC-FVC was $\geq 200 \mathrm{~mL}$.

In the present study, the spirometry results obtained with the combined use of FVC and SVC maneuvers changed the functional diagnosis that had been established with the use of FVC maneuvers alone. Of the 73 patients whose spirometry results were normal when FVC maneuvers were used in isolation, 21 were diagnosed with OLD when FVC and SVC maneuvers were used in combination. It has been reported that the prevalence of COPD in patients with mild disease is higher when assessed by $\mathrm{FEV}_{1} / \mathrm{SVC}$ than when assessed by $\mathrm{FEV}_{1} / \mathrm{FVC}^{(25)}$ Therefore, the $\mathrm{FEV}_{1} / \mathrm{SVC}$ ratio plays an important role in revealing airflow limitation in smokers with respiratory symptoms and impaired quality of life presenting with normal $\mathrm{FEV}_{1} / \mathrm{FVC}$, thus contributing to an early diagnosis of COPD. However, in the present study, a $\triangle$ SVC-FVC $\geq 200 \mathrm{~mL}$ was found to be independent of the severity of OLD, a finding that is inconsistent with those of other studies. $(4,5)$

The use of SVC maneuvers in combination with FVC maneuvers changed the results of spirometry in 8 of
28 cases of OLD with reduced FVC (those 8 being reclassified as cases of OLD) and in 12 of 32 cases of NLD (those 12 being reclassified as normal cases $[n=4]$ or as cases of OLD [ $n=8]$ ). VC accounts for approximately $75 \%$ of TLC. ${ }^{(19)}$ A finding of normal SVC is important because it can prevent the need for plethysmography in selected cases (given the difficulty of access to the test and the associated health care costs), especially in those in which a diagnosis of restrictive lung disease is less likely. However, a $\triangle$ SVC-FVC $\geq$ $200 \mathrm{~mL}$ failed to predict normal TLC in our sample.

In our initial logistic regression model, weight and a BMI $>30 \mathrm{~kg} / \mathrm{m}^{2}$ were predictors of a $\triangle$ SVC-FVC $\geq 200$ $\mathrm{mL}$. The association between weight and $\triangle$ SVC-FVC might be due to premature airway closure, given that there was no association with sGaw. Data from a large study suggest that $\triangle$ SVC-FVC is proportional to the increase in BMI, suggesting that obesity reduces FVC more than it does SVC; in contrast, in individuals with normal BMI and without OLD, SVC can be lower than FVC. ${ }^{(10)}$

Wang et al. ${ }^{(26)}$ divided their study sample into two groups, namely those with SVC = FVC and those with SVC > FVC, and found that $65 \%$ of the sample had SVC > FVC, a finding that was more common in older individuals. In the present study, age was not associated with $\triangle$ SVC-FVC; however, the mean age of our sample was considerably high (i.e., 59 years), and it was impossible to establish a comparison with younger individuals.

Lung volumes (TLC, FRC, SVC, and IC) were predictors of a $\triangle$ SVC-FVC $\geq 200 \mathrm{~mL}$, although only in the crude logistic regression analysis. Markers of airflow limitation (reduced $\mathrm{FEV}_{1} / \mathrm{FVC}$ and $\mathrm{FEV}_{1} / \mathrm{SVC}$ ) and findings of air trapping (such as increased FRC and reduced IC/TLC) ${ }^{(24)}$ were independent predictors of a $\triangle$ SVC-FVC $\geq 200 \mathrm{~mL}$.

The magnitude of $\triangle$ SVC-FVC correlated negatively with RV and positively with FRV. This was confirmed by our logistic regression model, in which FRV (although not RV) was independently associated with the probability of a $\triangle S V C-F V C \geq 200 \mathrm{~mL}$. This might be due to the fact that measured VC is higher during a SVC maneuver because of reduced thoracic gas compression, leading to reduced RV if we assume that TLC remains unchanged. Conversely, during a FVC maneuver, increased thoracic gas compression can result in airflow limitation, leading to reduced FVC and, consequently, increased FRV. 
Multiple logistic regression analysis showed that improvements in $\mathrm{FEV}_{1}$ and $\mathrm{FVC}$ after bronchodilator administration were more common in the $\triangle$ SVC-FVC $\geq 200$ group than in the $\Delta$ SVC-FVC $<200$ group. This raises the question of whether significant or nonsignificant bronchodilator response can differentiate between true obstruction and a variant of normality, respectively, in individuals with an isolated finding of $\triangle \mathrm{SVC}-\mathrm{FVC} \geq 200 \mathrm{~mL}$. In the present study, no association was found between $\triangle S V C-F V C$ and OLD or restrictive lung disease/NLD.

The present study has some limitations. Strict inclusion criteria resulted in a limited sample size. In addition, there was no control group (comprising healthy individuals); most of the study sample consisted of diseased individuals.

Future studies should determine whether $\triangle$ SVC-FVC can predict exercise-induced hyperinflation and its association with the small airways (as assessed by imaging and biochemistry).

In conclusion, the use of an SVC maneuver appears to reduce the prevalence of NLD. Although it is possible that $\triangle$ SVC-FVC is due to airflow limitation and air trapping, it might be due to dynamic compression of the airways during exercise. Individuals with a $\triangle S V C$ FVC $\geq 200 \mathrm{~mL}$ are more likely to have a significant bronchodilator response.

\section{REFERENCES}

1. Pellegrino R, Viegi G, Brusasco V, Crapo RO, Burgos F, Casaburi R, et al. Interpretative strategies for lung function tests. Eur Respir J. 2005;26(5):948-68. https://doi.org/10.1183/09031936.05.00035205

2. Klingele TG, Staub NC. Alveolar shape changes with volume in isolated, air-filled lobes of cat lung. J Appl Physiol. 1970;28(4):411-4 https://doi.org/10.1152/jappl.1970.28.4.411

3. Leith DE, Mead J. Mechanisms determining residual volume of the lungs in normal subjects. J Appl Physiol. 1967;23(2):221-7. https:// doi.org/10.1152/jappl.1967.23.2.221

4. Chhabra SK. Forced vital capacity, slow vital capacity, or inspiratory vital capacity: which is the best measure of vital capacity? J Asthma. 1998:35(4):361-5. https://doi.org/10.3109/02770909809075669

5. Brusasco V, Pellegrino R, Rodarte JR. Vital capacities in acute and chronic airway obstruction: dependence on flow and volume histories. Eur Respir J. 1997;10(6):1316-20. https://doi.org/10.1183/ 09031936.97.10061316

6. Sutherland PW, Katsura T, Milic-Emili J. Previous volume history of the lung and regional distribution of gas. J Appl Physiol. 1968;25(5):566-74. https://doi.org/10.1152/jappl.1968.25.5.566

7. Chan ED, Irvin CG. The detection of collapsible airways contributing to airflow limitation. Chest. 1995;107(3):856-9. https://doi.org/10.1378/ chest.107.3.856

8. von Westernhagen F, Smidt U. The significance of the difference between slow inspiratory and forced expiratory vital capacity. Lung. 1978;154(4):289-97. https://doi.org/10.1007/BF02713545

9. Barros AR, Pires MB, Raposo NM. Importance of slow vital capacity in the detection of airway obstruction. J Bras Pneumol. 2013;39(3):31722. https://doi.org/10.1590/\$1806-37132013000300008

10. Fortis S, Corazalla EO, Wang Q, Kim HJ. The difference between slow and forced vital capacity increases with increasing body mass index: a paradoxical difference in low and normal body mass indices. Respir Care. 2015;60(1):113-8. https://doi.org/10.4187/respcare.03403

11. Aguiar VA, Beppu OS, Romaldini H, Ratto OR, Nakatani J. Validity of a respiratory modified questionnaire (ATS-DLS-78) as a tool of an epidemiologic study in Brazil [Article in Portuguese]. J Pneumol. 1988;14(3):111-6.

12. Pereira CA, Sato T, Rodrigues SC. New reference values for forced spirometry in white adults in Brazil. J Bras Pneumol. 2007;33(4):397406. https://doi.org/10.1590/S1806-37132007000400008

13. Neder JA, Andreoni S, Castelo-Filho A, Nery LE. Reference values for lung function tests. I. Static volumes. Braz J Med Biol Res. 1999;32(6):703-17. https://doi.org/10.1590/S0100879X1999000600006

14. Miller MR, Hankinson J, Brusasco V, Burgos F, Casaburi R, Coates A, et al. Standardisation of spirometry. Eur Respir J. 2005;26(2):319-38. https://doi.org/10.1183/09031936.05.00034805

15. Wanger J, Clausen JL, Coates A, Pedersen OF, Brusasco V, Burgos $F$, et al. Standardisation of the measurement of lung volumes. Eur Respir J. 2005;26(3):511-22. https://doi.org/10.1183/09031936.05.0 0035005

16. Sociedade Brasileira de Pneumologia e Tisiologia. Diretrizes para testes de função pulmonar. J Pneumol. 2002;28(Suppl 3):S1-S82.

17. Pereira CA, Moreira MA. Pletismografia - resistência das vias aéreas. In: Diretrizes para Testes de Função Pulmonar. J Pneumol. 2002;28(Suppl 3):S39-S54

18. Viljanen AA, Viljanen $B C$, Halttunen $P K$, Kreus KE. Body plethysmographic studies in non-smoking, healthy adults. Scand J Clin Lab Invest Suppl. 1982;159:35-50. https://doi. org/10.1080/00365518209168379

19. Pereira CAC, Rodrigues SCS. Bases da Interpretação. In: Salge JM, Izbicki M, Rodrigues SCS, Rodrigues Junior R, editors. Série Atualização e Reciclagem em Pneumologia - SPPT: Função Pulmonar. 1st ed. São Paulo: Atheneu, 2012. p. 13-44.

20. Golshan M, Amra B, Soltani F, Crapo RO. Reference values for lung volumes in an Iranian population: introducing a new equation model. Arch Iran Med. 2009;12(3):256-61.

21. Esteban C, Quintana JM, Egurrola M, Moraza J, Aburto M Pérez-lzquierdo J, et al. Classifying the severity of COPD: are the new severity scales better than the old? Int J Tuberc Lung Dis 2009;13(6):783-90

22. Soares AL, Pereira CA, Rodrigues SC. Spirometric changes in obstructive disease: after all, how much is significant? J Bras Pneumol. 2013;39(1):56-62. https://doi.org/10.1590/S180637132013000100008

23. Pistelli F, Bottai M, Viegi G, Di Pede F, Carrozzi L, Baldacci S, et al. Smooth reference equations for slow vital capacity and flow-volume curve indexes. Am J Respir Crit Care Med. 2000;161(3 Pt 1):899-905. https://doi.org/10.1164/ajrccm.161.3.9906006

24. Zeng S, Tham A, Bos B, Jin J, Giang B, Arjomandi M. Lung volume indices predict morbidity in smokers with preserved spirometry. Thorax. 2019;74(2):114-124. https://doi.org/10.1136/ thoraxjnl-2018-211881

25. Torén K, Olin AC, Lindberg A, Vikgren J Schiöler L, Brandberg J, et al. Vital capacity and COPD: the Swedish CArdioPulmonary biolmage Study (SCAPIS). Int J Chron Obstruct Pulmon Dis. 2016;11:927-33. https://doi.org/10.2147/COPD.S104644

26. Wang W, Ma D, Li T, Ying Y, Xiao W. People with older age and lower FEV1\% pred tend to have a smaller FVC than VC in pre-bronchodilator spirometry. Respir Physiol Neurobiol. 2014;194:1-5. https://doi. org/10.1016/j.resp.2014.01.003 